\title{
Reasons for the Loss of Sun Shiyi's Poems and the Oblivion of His Poetic Fame
}

\author{
Suxiang $\mathrm{Yu}$ \\ School of Literature \\ Tibet University \\ Lhasa, China
}

\author{
Juntao Wang \\ School of Literature \\ Tibet University \\ Lhasa, China
}

\begin{abstract}
Sun Shiyi was a famous political figure. As a poet, he also took a place in the poetry circles at that time. But a lot his poems were lost, and his poetic fame was not well-known. His existing poems are left without anybody to care for them. The reasons are complex. This article has analyzed and discussed the reasons for the loss of his poems and the oblivion of his poetic fame by exploring the forever disappearance of history, understanding the creation of poetry and dissemination mentality in the mid-Qing Dynasty, and studying the significance of social relationship and personal control to individual and literature in the Qianlong and Jiaqing period.
\end{abstract}

Keywords-Sun Shiyi; Collection of Baiyi Shanfang Poems; lost; oblivion

\section{INTRODUCTION}

Sun Shiyi (1720-1796) had a great influence in the political arena during the Qianlong period of the Qing Dynasty. He was a Bachelor of Wenyuan Pavilion. His Collection of Baiyi Shanfang Poems has been preserved to now. His poems had a high literary and cultural value. However, in the literary history and poetry history of Qing Dynasty, Sun Shiyi's name did not exist. The poet, who had a collection of poems in the Jiaqing period, has been forgotten for over 200 years.

\section{SUN SHIYI AND COLLECTION OF BAIYI SHANFANG POEMS}

The name of Sun Shiyi is quite unfamiliar to the public at present, but at that time he was a great figure. He served as a cabinet secretary, editor, Taichang Shaoqing, provincial administrative commissioner, minister, governor and other official positions. His deeds can be seen in many historical biographies. Sun Shiyi's biographies are found in the Manuscripts of Qing History, Biographies of Qing History, Biographical Sketch of State Affairs, Words and Deeds of State Ministers and Preliminary Editions of National Literature.

In the late Qianlong period of Qing Dynasty, the governing group was corrupted. There were many wars and uprisings, and the political situation was turbulent. Emperor Qianlong relied on such ministers as Sun Shiyi and Fu Kangan to rectify the law of the imperial court and save the great decline. Sun Shiyi's life has been tortuous and legendary. He had experienced several ups and downs. He had been a variety of civilian officers. He had also been supervisor of the frontier of the army and guarding the country. His poems were written in such an environment.

Collection of Baiyi Shanfang Poems was named for stones Sun Shiyi liked to collect strange stones. It is said that he has got one hundred and one beautiful stones. Therefore, he named his study "Baiyi Shanfang", and his poetry collection also has this name. There are 12 volumes and 1073 poems in the extant collection of poems. Most of Sun Shiyi's poems collected were after his pre-becoming of an official and before his death in the battlefield at the age of 76. Some of them were praised by famous poetry critics in the Qing Dynasty. Liu Jinzao of the Qing Dynasty once praised that "his poems were vigorous and brilliant, and cast its radiance far and wide, which were not concealed by his achievements" [1]. The praise of "cast its radiance far and wide" is somewhat excessive, but its poems can integrate many families being a harmonious whole.

Sun Shiyi's poems were highly appreciated by the people at the time. He has been closely associated with poets of Xingling School such as Yuan Mei and Zhao Yi, and also with Yao Ding, Yao Nai and Weng Fanggang. His poems turned to be more instructive, not bound by the sects at that time, and his style changed many times over time, which can be said to be self-contained. His achievements should not be ignored.

\section{REASONS FOR THE LOSS OF HIS POEMS}

The poems collected in Collection of Baiyi Shanfang Poems are only a part of Sun Shiyi's poems, not all of them. There are still a lot of lost poems. The reasons are as follows:

\section{A. The Attitude of Editors}

The loss and change of some of Sun Shiyi's poems were related to the attitude of the editor. The collection was printed in 21 st Jiaqing year, when Sun Shiyi had died. Sun Jun, Sun Shiyi's grandson, completed the publication of the collection of poems. Sun Jun said in the Afterword to Collection of Baiyi Shanfang Poems: "All poems before Ling Nan were recorded by Grandpa Sun Shiyi himself. The poems after this poem were found in his suitcase after his death in the first Jiaqing year. A lot of them were written on "scraps of paper". One or two verses or a complete poem was obliterated and smeared, so this part was not included" [2]. His words contained two important messages. First, poems before Ling Nan were edited and recorded by Sun Shiyi himself. Second, poems after Ling 
Nan were found by his grandson Sun Jun in a suitcase when he buried his grandpa. Among them, damaged poems and doubtful poems were not included in the collection of poems. Sun Jun sorted out and printed the rest poems. The first point will be analyzed in detail afterward, and here we first analyze the second point. The collection of poems Sun Jun collected and printed was the Collection of Baiyi Shanfang Poems in edition of 21st Jiaqing year, and the Collection of Baiyi Shanfang Poems collected in Poetry Collection of Qing Dynasty and Renewal of Siku Quanshu was all photocopies of this edition, which is the only version we can see today. When Sun Jun was sorting out his ancestor Sun Shiyi's works, what he saw was the poem manuscripts in the suitcase. Sun Shiyi's death was sudden. Before that, Sun Shiyi had been on the battlefield and had not had time to carefully collect his poem manuscripts. Therefore, the number of "scrap paper" should be quite large. Naturally, some of them were not final manuscripts, and some of them were drafts with obvious traces of amendment. "One or two verses or a complete poem was obliterated and smeared", and none of these poems are included in the Collection of Baiyi Shanfang Poems.

Some of the poems that are not included in the collection can still be seen elsewhere. Some of Sun Shiyi's poems and essays were found in the anthologies and letters of people at that time. Some of them were not included in the Collection of Baiyi Shanfang Poems. For example, in Zhao Yi's Oubei Collection, there were poems in letter between Zhao Yi and Sun Shiyi. We can see it in Zhao Yi's Sun Bushan Fanbo Wrote Letters from Far South of Yunnan, and Recorded His Opinions on Passing through Songguan Pass. The pass was outside Tengyue Prefecture, on the road of past expedition of Bo Wenzhong to Myanmar. Bushan had followed him, so he recorded this and wrote to me. When I read it, I can feel his feelings from his words. To memory him, I wrote it, the poem of Sun Shiyi without title was attached in the attachment [3]. This poem was not recorded in the Collection of Baiyi Shanfang Poems. Of course, this poem is not necessarily within the scope of those "scraps of paper". This example can prove that some of Sun Shiyi's poems are not in the Collection of Baiyi Shanfang Poems, but may exist elsewhere. The poems are mostly works in contact with his friends, and Sun Jun didn't saw them, or only saw the smeared and unclear drafts. Sun Shiyi didn't record them in his collection in advance. The author speculates that there are two reasons. First, Sun Shiyi was too busy to put the poems in his correspondence with friends, relatives and colleagues into his poems collection in time, which may be forgotten later. Secondly, Sun Shiyi may have entered his works for letters with others into the poetry collection in time. The poems in the collection, especially those before Ling Nan, have been sorted out (see the preceding paragraph). Later, after constant consideration and revision, some poems have been deleted for some reasons. Sun Jun couldn't see or did not see the complete poem, so he did not enter the poem collection.

Therefore, the loss or change of some of Sun Shiyi's poems stemmed from Editor Sun Jun's cautious attitude towards ancestors' poems.

\section{B. Sun Shiyi's Attitude Towards His Poems}

Sun Shiyi's attitude towards his poems was very serious. After repeated consideration, it is also common sense that there are changes in one's poems from time to time. Sun Jun found many unsettled manuscripts when he was sorting out it. That was Sun Shiyi's trace of revising the manuscripts of poems. In Su Qiji's preface to the Collection of Baiyi Shanfang Poems, "so, with different paths, the responsorial poems are few. The effort for creation a work and a wonder of a verse is not without doubt mutually discussing. However, although I do not know his ambition, I know his diligent study and very few can match with him" [4]. It can be seen Sun Shiyi's attitude toward poetry. One by one, he discussed with his friends. Su Qiji, with his heart, praised it.

This is another proof in Sun Jun's Afterword to Collection of Baiyi Shanfang Poems: "Grandpa wrote poems to spend his rest time, and he asked his friend Shuangji Taoist Hu Longyou to write preface to the collection of poems. The preface was lost before the publication of this book. Before he became Jinshi, he was famous for his poems. He ever was editor of ancient books and records. After he was enrolled as official, he upheld his integrity. In the past three decades, he was busy for official duties. But he did not quit writing poems" [5]. This passage proves that the poems in the Collection of Baiyi Shanfang Poems were constantly increasing or decreasing. Before Sun Shiyi became an official, this collection had already existed. Hu Longyou, a Shuangji Taoist, had written a preface to this poem collection, and Hu Longyou's preface was lost. After that, although Sun Shiyi had many things to do when he was an official, he still insisted on composing poems and constantly enriched this collection of poems. This can prove that the poems in Collection of Baiyi Shanfang Poems could be changed at any time with the increasing of Sun Shiyi's experience.

When Sun Shiyi wrote new poems, he added new poems to his collection; if he was not satisfied with previous poems, he would re-amend them and delete or revise them from the collection. Some of the poems were completely gone, some of them were still in existence, and there were many changes in the words. For example, Zhao Yi attached two poems of Sun Shiyi in the attachment of Repressing Regard and Concern and Replying to Bushan who Wrote to Me in Guilin Last Year, and Now Moved to East Guangdong [6]. They are the same work in Letter to Zhaoyi in Guilin [7] in Collection of Baiyi Shanfang Poems, but the words and sentences are quite different.

For many times, he changed the contents of previous poems. "Compared 33 poems collected in Journey to Tibet with related 33 poems in Collection of Baiyi Shanfang Poems, almost each of them has changes when it is included in the official collection. Of course, most of them are just different in words. But 14 of them are totally different. So why are there so many differences between Sun's poems in Journey to Tibet and those in Collection of Baiyi Shanfang Poems? The answer can only be that when Sun Shiyi collected them finally, he made great changes and additions and deletions. The poet's revision of his poems is beyond reproach, fully understandable and, in a sense, inexorable. What's more, Sun Shiyi's poems, written in a 
hurry to ensure that the army of Fu Kang'an had sufficient military reserves, were deliberated in his spare time after the event, which inevitably made him feel deficient. It is common sense to use the opportunity of collecting to revise them" [8], Mr. Gu Zheqin mentioned in Research on Poems of Tibetan Affairs of Qing Dynasty toward Sun Shiyi's attitude toward Tibetan poetry. It shows that the change of Mr. Sun's poems was related to Sun Shiyi's rigorous attitude.

Sun Shiyi's deletion and revision of old works was also a follow-up of the rigorous tradition of self-introspection of ancient scholars. It was a re-examination of the poems and manuscripts which were formed in a hurry in the leisure of government affairs. Some of them were negated. It can also be said that it was out of a kind of literary consciousness, which was very common in the Qing Dynasty. As Fang Dongshu said in the Preface to the Banzi Collection, "at eleven, I would try to imitate Fan Yun's Shenhuoshu, which was appreciated by the ancestors of the countryside. It was because people liked poems and I was happy about it. In Bingzi year, I suffered an illness and was discouraged about writing. So, there are a few works and I burned some" [9].

Under the care of another situation or perspective, it is easy to see the shortcomings or mediocrity of the old works by reexamining the works and consciously examining them. For works of poor quality or mediocrity, the author is shy of being evaluated in public, so that he can choose, modify or eliminate them first. This is a way of self-filtering and promotion. It is a higher requirement for us.

Therefore, the missing part of Mr. Sun's poems was related to his rigorous attitude.

\section{Lost in the Frontier Snowfield}

The collection of poems is legendary as well as the master's experience. On Sun Shiyi's journey to Tibet in his later years, Zhou Ailian, as Sun Shiyi's army assistant, was responsible for keeping Sun Shiyi's poems and manuscripts, which were recorded in Zhou Ailian's Journey to Tibet. "Wenjing had written over a hundred poems on the way from Jianlu to Tibet while he had rest time after military affairs. As I assisted him to pass Danda Mount, the works were lost in snow cellar and only a few of them were preserved" [10]. Zhou Ailian did not keep these poems well and lose them in ice cellar together with his own poems, which resulted in the loss of some poems. This matter can be confirmed in Xiao Lian Lost My Poem Manuscripts in Danda Mount and I Knew Xiao Lian Lost His Poems with Mine the Next Day, and Wrote another Poem, Asking Xiao Lian [11], two poems in Sun Shiyi's Collection of Baiyi Shanfang Poems, which is also recorded in Sun Jun's Afterword to Collection of Baiyi Shanfang Poems [12].

But unexpectedly, the poems Zhou Ailian thought being lost were still preserved in Collection of Baiyi Shanfang Poems. For example, Hutukutu, Capital of Chouchang was still in Collection of Baiyi Shanfang Poems. Zhou Ailian thought that "no one can remember because they have lost"[13]. How could it appear in Sun Shiyi's poem collection completely? The author believes that Sun Shiyi recalled lost poems by memory and recorded them in the collection of poems. But even if Sun Shiyi's memory was superb, he would inevitably forget some poems, which results in that the later work was not completely consistent with the earlier works. Journey to Tibet has recorded many poems of Sun Shiyi when he traveled to Tibet, three of which were not found in the Collection of Baiyi Shanfang Poems.

It is one of the reasons for the loss of Sun Shiyi's late poems.

\section{Political and Social Reasons}

Political and social pressures are also the reasons for the loss of some of Sun Shiyi's poems. For some political and social reasons, Sun Shiyi or Sun Jun deliberately deleted some poems.

When Sun Shiyi served as governor of Yunnan, Governor Li Shiyao corrupted and misused the law, and Sun Shiyi got involved. Sun Shiyi was dismissed and sent to Yili. When confiscating his properties, the emperor saw his honesty and uprightness and changed his order and gave him the post of editor of Hanlin Academy, and ordered him to compile and proofread Siku Quanshu. Sun Shiyi had some political insights at this time, and wrote a poem about it (with no title) [14] to express his views on dealing with official and personnel relations for politics. This poem is not included in the collection. Obviously, the poem touched sensitive areas and was not suitable for publicity.

Sun Shiyi was the commander of the Annan Battle. He won the war first and then lost. When he won the battle, Sun Shiyi wrote ten poems of Southern Expedition to express his proud ambition. Sun Shiyi blamed himself for the failure of the war and was unwilling to preserve some related poems and essays. Ten poems of Southern Expedition were not included in the poetry collection. The poems of Southern Expedition [15], which can be seen now, are collected in the anthology of others.

Because of the evaluation of Sun Shiyi by Emperor Jiaqing after he was in power, many people mocked and denigrated Sun Shiyi, which led to the deletion of some relevant information. It is a pity, for example, the imperial clansman Zhao Lian said "I've ever written poems to cherish the memory of Sun Weijing after his death. But many officials ridiculed and scorned him and burned his manuscripts"[16]. It shows that the destruction of Sun Shiyi's data in Jiaqing Dynasty was very serious. These manuscripts should include some of Sun Shiyi's poems.

In the early and middle period of Qing Dynasty, especially in Qianlong Dynasty, the upper rulers kept vigilance and precaution against the literati stratum at all times. They had a strong sense of precaution against the writing, and the literary inquisition was a frequent occurrence. The relationship between literati and the ruling class showed extreme tension, especially when it involved the current political situation of the supreme rulers and ruling groups. Because of Sun Shiyi's special status, experience and background, his words and deeds had great influence, which made him and other people concerned had to be cautious and avoid leaving behind a lot of troubles. 
To sum up, Sun Shiyi's poetry anthology was altering and changing all the time. From the first draft to the repeated revision, from the loss of the manuscript to the magical preservation, to the final compilation of a collection of poems, the experience of this collection of poems is not ordinary. Through the twists and turns, it is hard-earned.

\section{THE REASONS FOR THE OBLIVION OF His POEMS}

Sun Shiyi's poetry was very successful. However, to this day, Collection of Baiyi Shanfang Poems was unfamiliar to readers, and let alone enter the academic field of vision. The reasons are as follows:

\section{A. Being Covered by His Achievements}

Sun Shiyi's achievements in political work were so outstanding that his achievements in poetry and prose were almost completely covered by his achievements, and his literary achievements are neglected. People who know Sun Shiyi only remember him as a political figure, and do not know his poetry achievements.

According to the General Examination of Continued Documents of the Qing Dynasty, "Shiyi's achievements were very great. His name was recorded in the history, so it is unnecessary for him to compete with literati for a place" [17]. In light of the logical thinking of that era, the name in achievement is greater than poetic fame. Sun Shiyi was very successful in his career. For many years, he was assigned as feudal officials and bachelors. He should not compete with literati by his poetry. Sun Jun also said: "my grandpa has a great ambition. He has both literary grace and warlike exploits, and was appreciated by the emperor. It was no longer for him to compete with poets"[18]. At that time almost all people thought so. Achievements have already been outstanding, so he should not compete with literati. Why Sun Jun published the Collection of Baiyi Shanfang Poems is because that he was his ancestor. There was another reason that "poems of my grandpa could help cultivate qualities of association, observation, affiliation and expression of emotion. His poems also contain political affairs. They are quite different with the poems of literati'[19]. His poems are different with lyric poems of literati. They have the function of cultivation, so Sun Jun published his collection of poetry.

From words of Liu Wenzao and Sun Jun, we can know that Sun Shiyi's fame of poetry was obliterated because of people's attitude towards his achievements and literary talent.

\section{B. Being Influenced by the Political Pressure of That Time}

The guidance of political public opinion has a great influence on the spread of Sun Shiyi's poems. Sun Shiyi's status was changing from time to time. Sometimes he was a scholar who hoped the imperial examinations would succeed in his official career. Sometimes he was a civil servant with complicated government affairs. Sometimes he commanded the army in the battlefield. People are always good at judging all aspects of a person according to his status, honor and disgrace. People at that time and future generations also see Sun Shiyi and his poems in the same way. His changing career and identity made the critics at that time and later generations treat his poems and essays with the ups and downs of the current comments. Sometimes they compliment and appreciate him, and sometimes they mock and ridicule him.

Just after the prevailing of literary inquisition during the reign of Qianlong, the newly ruling Emperor Jiaqing began to clear up the old forces, and his evaluation of Sun Shiyi was negative, with a lot of dissatisfaction. Because of the change of the emperor's attitude, lots of scholars and humanists change their view according to circumstances. Poets in literary circles were too urgent to avoid misfortune. Naturally, they dared not or disdained to spread the poetic fame of Sun Shiyi.

Under the pressure of the current situation, some people burned up the poems and articles related to Sun Shiyi, which led to the destruction of a lot of materials. It is a pity. As Zhao Lian said before it was a reflection of people's attitude at that time.

Not only that, someone even sneered at and denigrated him for fear of being said to have had good relations with Sun Shiyi. Even if being looked after by him for many times, Yuan Mei, a Xingling scholar who was ever deeply touched by Sun Shiyi, immediately turned hostile. In the Suiyuan Poetry Talks [20], he tried his best to clear up the relationship with him, and even there were some words of slander and abuse. We can see the mentality of literati.

The pressure of political current leads to the failure of effective spread of Sun Shiyi's works and oblivion of his poetic fame.

\section{Being Influenced by the Literature Research Situation in Qing Dynasty}

The academic circles did not know enough about the literature of the Qing Dynasty, and did not pay enough attention to the poetry in Qing Dynasty. Relatively speaking, the study of literature in the Qing Dynasty is generally less and shallow. At present, the recognition of the stylistic features of Qing Dynasty poetry is still in the shallow stage of discovery, sorting out and exploration and it cannot reach the level of consensus as mature as Tang and Song Dynasties.

The society in the early Qing and the late Qing Dynasty was in a period of turbulent change, which could better reflect the changes of the country and society. More and more attention was paid to the study of poetry in these two periods, while the poetry in the middle period of Qianlong and Jiaqing was ignored. During this period, the study of poetry, prose and writers mainly focused on a limited number of well-known writers and works, paying more attention to such famous writers as Qian Qianyi, Wu Weiye, Yuan Mei and Zhao Yi. Sun Shiyi's achievements in poetry did not arouse the attention of the academic circles. Poets and works that have not been noticed in literary history generally are not known or seen by ordinary scholars or readers. Although Sun Shiyi's poetry had been printed in the Jiaqing period, it has rarely been circulated. If Mr. Wu Fengpei did not occasionally meet the Collection of Baiyi Shanfang Poems in the bookshop, realized its value, bought it into the library, and compiled some poems related to Tibet into Sichuan-Tibet Travel Collection, Sun Shiyi's poems still could not enter the academic field of vision. It was not 
until the new century that the Jiaqing photocopy of the Collection of Baiyi Shanfang Poems was included in the Renewal of Siku Quanshu (in 2002) and Collection of Poetry and Literature of Qing Dynasty (in 2010), that readers finally had the opportunity to see the complete edition of Sun Shiyi's poetry collection.

The number of poetry works in Qing Dynasty is very large. Faced with the vast number of works, it is difficult for even interested readers to read them one by one with their own efforts. It can be said that up to now, few scholars or readers have known the name of Sun Shiyi and read the whole Collection of Baiyi Shanfang Poems. Such a situation not only exists in Sun Shiyi, a poet of the Qing Dynasty, but also in other unknown writers of the Qing Dynasty.

The reason why Sun Shiyi's poetic fame and poems were obscured was also influenced by the literary research situation of Qing Dynasty.

\section{CONCLUSION}

Sun Shiyi's poems are largely lost, and his poetic fame is unknown, as well as his Collection of Baiyi Shanfang Poems, among which the reasons are very complicated. There are four reasons for the loss of his poems: the attitude of the editor, Sun Shiyi's attitude to his poems, the loss in the snow cellar, political and social pressure. The reasons for the oblivion of his poetic fame are as follows: being covered by his achievement, being impacted by the pressure of political situation and the literary research situation of Qing Dynasty. It has deep significance to understand the history of that time, explain the creation and communication mentality of the poets represented by Sun Shiyi, and study the influence of the political and social relations of the Qianlong and Jiaqing period on the creation and dissemination of literature by studying the reasons for the loss of Sun Shiyi's poems and oblivion of his poetic fame.

Sun Shiyi, a statesman and poet with special literary quality and life attitude, was a typical figure of the Han-official group from bottom to top in the Qianlong period. His ups and downs of life course and his living wisdom and poetry creation were the epitome of the scholar-bureaucrat class in the midQing Dynasty. The formation of this special quality and its guiding significance should be paid attention to. However, a lot of Sun Shiyi's poems have been lost. His name as a poet has long been forgotten in the ashes of history, which is a pity!

\section{REFERENCES}

[1] Liu Jinzao. General Examination of Continued Documents of the Qing Dynasty: Vol. 279. Beijing: Commercial Press, 1936: 10246, 10246. (in Chinese)

[2] Sun Jun. Afterword to Collection of Baiyi Shanfang Poems. Renewal of Siku Quanshu: Vol. 1433. Shanghai: Shanghai Ancient Books Publishing House, 2002: 515, 515, 515, 515 and 515. (in Chinese)

[3] Hua Fu. Zhao Yi's Poems. Tianjin: Tianjin Ancient Book Publishing House, 1996: 696, 804. (in Chinese)

[4] Su Qiji. Preface to Collection of Baiyi Shanfang Poems. Renewal of Siku Quanshu: Vol. 1433. Shanghai: Shanghai Ancient Books Publishing House, 2002: 361. (in Chinese)

[5] Same as [2]
[6] Same as [3]

[7] Sun Shiyi. Collection of Baiyi Shanfang Poems. Renewal of Siku Quanshu: Vol. 1433. Shanghai: Shanghai Ancient Books Publishing House, 2002:455, 478. (in Chinese)

[8] Gu Zheqin. Study on Tibetan Poems in Qing Dynasty. Guangzhou: Zhongshan University Press, 2017: 447. (in Chinese)

[9] Fang Dongshu. Preface to Banzi Collection. Collection of Poetry and Literature in Qing Dynasty: Vol. 507. Shanghai: Shanghai Ancient Books Publishing House, 2010: 1. (in Chinese)

[10] Zhou Ailian. Journey to Tibet. Proofread by Zhang Jianghua. Beijing: Chinese Tibetan Studies Press, 2006: 47, 48. (in Chinese)

[11] Same as [7]

[12] Same as [2]

[13] Same as [10]

[14] Chen Jieyan. Sigh of a Passenger ·Jieyan's Poems on History. Beijing: Chinese History and Culture Publishing House, 2012: 1574. (in Chinese)

[15] Zhang Yinhuan. Diaries about Three Prefectures. Proofread by Yan Kun. Changsha: Yuelu Press, 2016: 167-170. (in Chinese)

[16] Zhao Lian. Xiao Ting's Miscellany: Vol. 10. Proofread by He Yingfang. Beijing: Zhonghua Book Company, 1980: 356. (in Chinese)

[17] Same as [1]

[18] Same as [2]

[19] Same as [2]

[20] Yuan Mei. Sui Yuan's Poems. Proofread by Wang Yingzhi. Nanjing: Jiangsu Ancient Book Publishing House, 2000: 649. (in Chinese) 